\title{
Identifying Drought Status in Duhok Governorate (Iraqi Kurdistan Region) from 1998 through 2012 using Landsat Time Series Dataset
}

\author{
Heman Abdulkhaleq A. Gaznayee ${ }^{1}$, Ayad M. Fadhil Al-Quraishi2* \\ ${ }^{1}$ Department of Forestry, College of Agriculture, Salahaddin University, Erbil 44003, Kurdistan Region, Iraq \\ (heman.ahmed@su.edu.krd) \\ ${ }^{2 *}$ Department of Environmental Engineering, College of Engineering, Knowledge University, Erbil 44001, Kurdistan \\ Region,Iraq. (ayad.alquraishi@gmail.com; ayad.alquraishi@knu.edu.iq) ORCiD (0000-0001-7732-129X) \\ Corresponding Author*
}

\begin{abstract}
Drought is a natural hazard that has a significant impact on the various aspects (i.e., economic, agricultural, environmental, and social). This study was carried out to evaluate drought severity and frequency during the growing season (April month) in Duhok Governorate, the Iraqi Kurdistan Region (IKR), for the period from 1998 through 2012 based on Landsat-based spectral indices. In this study, fifteen mosaics assembled for fifteen years consist of two scenes of Landsat time series, in a total of thirty TM and ETM+ images (WRS2: 170/34 \& 170/35) acquired in 1998 to 2012. Annual precipitation data were collected from eighteen meteorological stations distributed in the (DUG) for the study period. Drought status was investigated using the Normalized Difference Vegetation Index (NDVI), Modified Soil Adjusted Vegetation Index (MSAVI2), and Normalized Difference Water Index (NDWI). The present study results showed an increase in drought severity and frequency in the (DUG) during the fifteen years, particularly in 2000 and 2008. Whereas the NDVI-based vegetation cover area reduced by $21.5 \%$ and $50.2 \%$ in 2000 and 2008, respectively. Additionally, the lowest values of the MSAVI2 (0.012 and 0.266 ) occurred in 2000 and 2008. As an MSAVI2 values reduction's result, the percentage of the vegetation cover reduction was $\mathbf{1 4 . 0 \%}$ and $23.9 \%$, respectively. Moreover, drop in precipitation averages have taken place in those two drought years 2000 and 2008 , as well as to a significant decrease in the vegetation cover. On the other side, the most significant shrinkage in Duhok Dam (DUD) was by $1.13,1.44$, and $1.36 \mathrm{~km}^{2}$ in 2007,2008 , and 2009 . It can be concluded that there are increasing drought episodes in the last two decades, declining in the water body surface area and the precipitation averages in the DUG from 1998 through 2012.
\end{abstract}

Keywords: Drought, Landsat, NDVI, MSAVI2, NDWI, Duhok.

Received: February 20, 2020 /Accepted: March 16, 2020 / Online: March 29, 2020

\section{INTRODUCTION}

According to Hangman (1984), drought is considered by many to be the most complex but least understood of all-natural hazards affecting more people than any other hazard [1]. Drought is recognized as an environmental disaster and has attracted the attention of the environmentalists, ecologists, hydrologists, meteorologists, geologists, and agricultural scientists [2]. Drought occurs in the Iraqi Kurdistan Region (IKR) as in the other semi-arid areas and continues to cause multiple adverse impacts.

The IKR is located in the north part of Iraq. In literature, Iraq is known as the fertile crescent, or the northern territories of Mesopotamia, and has been under investigation by different researchers [3-5]. Severe drought has affected the IKR as well as the other parts of Iraq throughout the last decades, which characterized by a dramatic drop in precipitation rates [6-8]. Various impacts can occur as a result of drought, such as the decline of groundwater resources, depletion in lakes/ reservoirs, shortage of drinking water, and reduced field crop and fodder availability [8-9]. From the agricultural point of view, vegetable production and fruit orchards predominate in the highprecipitation zone in the northern parts, while wheat fields occupy most of the medium-precipitation zone, and barley is the main crop in the low-precipitation zone. Winter wheat and barley are planted in the fall season (Oct.-Nov.) and harvested in the late spring (Apr.-Jun.) following the precipitation pattern [5,10-11]. 
There are two phases in the sequence of drought development: First, the meteorological drought when a drought event starts initially with a prolonged shortage in precipitation. Second, this shortage in precipitation leads to reduce available soil water and limited- vegetation cover; this is known as agricultural drought [12-13]. Remote sensing (RS) and Geographical Information Systems (GIS) techniques are increasingly being regarded as a useful drought detection technique [14]. RS technology in its current state of the science can be in the help of predicting, mitigating, and monitoring of drought. The latter is successfully carried out the world over using indices derived from optical RS data.

On the other side, spectral drought indices have been widely utilized to study and map drought [14-15]. Data from various satellites can be utilized for the purpose irrespective of the perspective of a researcher, whether it is agricultural, meteorological, or hydrological. These data enable us to understand the manifestations of drought in a larger area more directly than through conventional methods, and all, in a less time-consuming manner [16].

Geo-information technology (GIS, RS, and Global Positioning System "GPS") is considered as a modern discipline of sciences, integrating an acquisition, modeling, analysis, and management of spatially referenced data $[8,17]$. Vegetation is the first environmental element, which is affected by drought. In the land surface system, it is a crucial component to link the environmental components, such as soil, air, water, and other environmental elements [18]. The main objective of this study is to identify drought status and frequency in Duhok Governorate (DUG), IKR in the years from 1998 through 2012 using Landsat satellites dataset and RS techniques.

\section{STUDY AREA}

Duhok Governorate (DUG) is selected as a study area. It is located between latitudes 36o18' - 37o20' N, and longitudes $42 \mathrm{o} 20^{\prime}-44 \mathrm{o} 17^{\prime} \mathrm{E}$, in the northwestern part of Iraq, at altitude $430-2,500 \mathrm{~m}$ above sea level, and it covers about 11,066 km2 [19]. Turkey surrounds it from the north, Syria from the west, Ninevah Governorate from the south, and Erbil Governorate (IKR) from the east (Fig. 1). DUG consists of seven districts, which are Duhok, Semel, Zakho, Amedi, Akre, Shekhan, Bardarash [5]. Duhok dam (DUD) is located on Rubar Duhok two $\mathrm{km}$ to the north of the Duhok city, between latitudes $36^{\circ}$ $52^{\prime}$ to $36^{\circ} 54^{\prime} \mathrm{N}$, and longitudes $42^{\circ} 59^{\prime}$ to $43^{\circ} 00^{\prime} \mathrm{E}$ [20].

\section{DATA AND METHODOLOGY}

The satellite data has been used in this study for 1998 through 2012. Landsat 4 and 5 imageries were downloaded from https://glovis.usgs.gov, and used to depict the vegetation coverage in the study area. All Landsat images which were used in this study acquired in April or May of 1998 through 2012. ERDAS Imagine 2015, ERDAS ER Mapper 2015, ArcGIS ver 10.7.1 were employed in this study for image processing and spatial analysis.

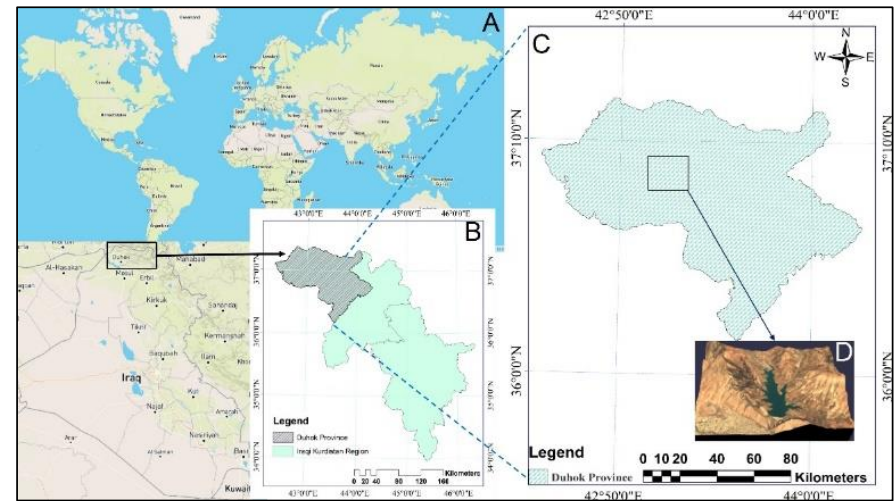

Fig. 1. (A) Location Map of Iraq (B) The IKR, (C) The study area (Duhok). (D) Location of DUD.

\section{A. Normalized Difference Vegetation Index (NDVI)}

The NDVI is the most widespread vegetation index, which has been utilized to map and monitor vegetation health status. To producing an NDVI image, a combination of Red and NearInfraRed (NIR) wavelengths reflectance and the Eq. 1 can be employed to calculate the NDVI image [21]. In healthy vegetation, there is a low reflection in the Red wavelength and high reflectance in NIR wavelength parts of the electromagnetic spectrum (EMS).

$$
N D V I=\frac{N I R-R e d}{N I R+R e d}
$$

It was found that the NDVI to be a strong vegetation signal and is mainly used to distinguish the vegetative area from the non-vegetative area [22]. Values of the NDVI index range between -1 to +1 , where -1 to 0 represents the non-vegetative features, such as a bare surface, water body, and built-up area. Nevertheless, an NDVI value higher than 0 depicts of vegetative cover. The main goal of this step is to isolate the non-vegetated areas, such as the built-up area, paved roads, bare soil, and only keep the vegetative [23].

\section{B. The Modified Soil-Adjusted Vegetation Index (MSAVI2)}

The MSAVI2 is a vegetation index, which employed in this study as a drought index. It has been revised from the Modified Soil-Adjusted Vegetation Index (MSAVI). As the previous SoilAdjusted Vegetation Index (SAVI), the MSAVI2 corrects the reflectance of areas with a great extent of exposed soil. This index is an enhancement of SAVI, which minimizes user error in setting a correction factor by providing higher reliably and easily calculating the correction factor of soil brightness [24]. The MSAVI2 values range from -1 to +1 and are computed upon pixel basis using Eq. 2 [25].

MSAVI2 $=\frac{2 \times \rho_{N I R}+1-\sqrt{\left(2 \times \rho_{N I R}+1\right)^{2}-8 \times\left(\rho_{N I R}-\rho_{R e d}\right)}}{2}$

Where $\rho$ is the reflectance in the NIR and Red bands. From the soil signal point of view, the role of soil signal in integrated spectral reflection, the MSAVI2 index is more efficient at depicting the vegetative area than the NDVI, particularly in barren soils. This behavior of MSAVI2 is effective and very 
beneficial in such areas of Iraq, where much of soil is exposed and has less or no vegetation.

\section{Normalized Difference Water Index (NDWI)}

As the indices mentioned above, thirty Landsat $5 \mathrm{TM}$ and Landsat 7 ETM+ images were employed for assessment temporal variations in the water surface area of DUD. The NDWI index is commonly used to calculate the water content. It was pixel-based computed using Eq. 3 [26]:

$$
N D W I=\frac{\rho_{N I R}-\rho_{S W I R}}{\rho_{N I R}+\rho_{S W I R}}
$$

The NDWI values are also range between -1 and +1 . Since this study is only interested in isolating the water body in the pixel, therefore, a thresholding technique was adopted to get the NDWI pixel values

\section{RESUlTS AND DISCUSSION}

\section{A. The NDVI}

The study results revealed that NDVI mean values varied from the lowest value of 0.107 in 2000 to the highest value of 0.305 in 2011 (Table 1). As noted, significant decreases were observed in the area of vegetation in the study area in 2000 and 2008 due to the extreme and severe years of drought that hit the IKR, including the study area, which led to a decrease in the area of the agricultural land (Fig. 5). The total area of vegetation based on NDVI in 2000 and 2008 were $2,415.0 \mathrm{~km}^{2}(21.5 \%)$ and $5,629.8 \mathrm{~km}^{2}(50.2 \% .0)$, respectively. Whereas, the vegetation cover has been shrunk by $48.8 \%$ and $20.1 \%$, respectively, based on the average of the vegetation area of 15 years. This decline can be mainly attributed to the drop in precipitation averages.

TABLE I. THE MAX, MIN, MEAN, OF NDVI VALUES AND THE AREA OF VEGETATIVE COVER IN THE STUDY AREA FOR THE YEARS 1998-2012.

\begin{tabular}{|c|c|c|c|c|c|c|}
\hline Year & $\operatorname{Max}$ & Mini & $\begin{array}{l}\text { Mean } \\
\text { NDVI }\end{array}$ & \multicolumn{2}{|c|}{$\begin{array}{l}\text { Veg. Cover } \\
\text { Area }\end{array}$} & \pm \\
\hline & & & & $\left(\mathbf{k m}^{2}\right)$ & (\%) & $(\%)$ \\
\hline 1998 & 0.99 & 0.10 & 0.283 & $8,618.6$ & 76.9 & 6.5 \\
\hline 1999 & 0.76 & 0.10 & 0.232 & $8,183.8$ & 73.0 & 2.6 \\
\hline 2000 & 0.99 & 0.02 & 0.107 & $2,415.0$ & 21.5 & -48.8 \\
\hline 2001 & 0.73 & 0.03 & 0.275 & $9,094.9$ & 81.1 & 10.8 \\
\hline 2002 & 0.69 & 0.06 & 0.231 & $8,244.2$ & 73.5 & 3.2 \\
\hline 2003 & 0.71 & 0.05 & 0.244 & $8,929.7$ & 79.7 & 9.3 \\
\hline 2004 & 0.70 & 0.04 & 0.218 & $7,898.7$ & 70.5 & 0.1 \\
\hline 2005 & 0.73 & 0.06 & 0.218 & $8,441.7$ & 75.3 & 4.9 \\
\hline 2006 & 0.62 & 0.02 & 0.159 & $6,433.3$ & 57.4 & -13.0 \\
\hline 2007 & 0.64 & 0.11 & 0.267 & $9,759.7$ & 87.1 & 16.7 \\
\hline 2008 & 0.70 & 0.02 & 0.180 & $5,629.8$ & 50.2 & -20.1 \\
\hline 2009 & 0.74 & 0.08 & 0.260 & $8,686.1$ & 77.5 & 7.1 \\
\hline 2010 & 0.69 & 0.13 & 0.290 & $7,901.5$ & 70.5 & 0.1 \\
\hline 2011 & 0.76 & 0.06 & 0.305 & $9,618.7$ & 85.8 & 15.4 \\
\hline 2012 & 0.72 & 0.01 & 0.211 & $8,459.7$ & 75.5 & 5.1 \\
\hline \multicolumn{3}{|c|}{ Average (15 years) } & 0.2 & $8,618.6$ & 76.9 & \\
\hline
\end{tabular}

\section{B. The MSAVI2}

The MSAVI2 and their transformations and derivatives are highly useful tools in monitoring drought. The high value of MSAVI2 indicates good and healthier vegetation. The Spatial pattern of vegetation cover from 1998 to 2012 is shown in Table 2 and Fig. 6. The value near or equal to zero indicates there is no vegetation; it is a barren land. The results showed that the lowest mean values $(0.012,0.266)$ of MSAVI2 were obtained in 2000 and 2008, respectively. This decline was more likely due to the decrease in annual precipitation, which is considered an essential factor that controls the decrease in the vegetation cover area and its MSAVI2 values in those years. The highest mean value of MSAVI2 (0.451 and 0.463) was obtained in 2001 and 2011. On the other side, it was noticed from the statistical analysis that the NDVI and MSAVI2 decreasing coincide with the decreasing of the Precipitation (Fig. 5 and Fig. 6)

TABLE II. THE MAX, MIN, MEAN, OF MSAVI2 VALUES AND THE AREA OF VEGETATIVE COVER IN THE STUDY AREA FOR THE YEARS 1998-2012.

\begin{tabular}{|c|c|c|c|c|c|c|}
\hline Year & Max & Mini & Mean Msavi2 & \multicolumn{2}{|c|}{$\begin{array}{c}\text { Veg. Cover } \\
\text { Area }\end{array}$} & \multirow{2}{*}{$\begin{array}{c} \pm \\
(\%)\end{array}$} \\
\hline & & & & $\left(\mathbf{k m}^{2}\right.$ & $(\%)$ & \\
\hline 1998 & 1.00 & 0.20 & 0.434 & 8,18 & 73.0 & 4.5 \\
\hline 1999 & 0.86 & 0.22 & 0.387 & 7,18 & 64.1 & -4.4 \\
\hline 2000 & 0.99 & 0.03 & 0.012 & 6,10 & 54.5 & -14.0 \\
\hline 2001 & 0.84 & 0.19 & 0.451 & 7,97 & 71.1 & 2.6 \\
\hline 2002 & 0.82 & 0.16 & 0.378 & 7,54 & 67.3 & -1.2 \\
\hline 2003 & 0.83 & 0.13 & 0.388 & 8,52 & 76.1 & 7.6 \\
\hline 2004 & 0.82 & 0.10 & 0.354 & 7,56 & 67.5 & -1.0 \\
\hline 2005 & 0.84 & 0.14 & 0.358 & 7,92 & 70.7 & 2.2 \\
\hline 2006 & 0.76 & 0.05 & 0.316 & 6,29 & 56.2 & -12.3 \\
\hline 2007 & 0.78 & 0.21 & 0.418 & 9,55 & 85.2 & 16.7 \\
\hline 2008 & 0.82 & 0.09 & 0.266 & 5,00 & 44.6 & -23.9 \\
\hline 2009 & 0.85 & 0.15 & 0.401 & 8,68 & 77.5 & 9.0 \\
\hline 2010 & 0.82 & 0.23 & 0.441 & 7,73 & 69.0 & 0.5 \\
\hline 2011 & 0.86 & 0.15 & 0.463 & 9,24 & 82.5 & 14.0 \\
\hline 2012 & 0.84 & 0.10 & 0.361 & 7,63 & 68.1 & -0.4 \\
\hline \multicolumn{3}{|c|}{ AVERAGE (15 YEARS) } & 0.384 & 7,67 & 68.5 & \\
\hline
\end{tabular}

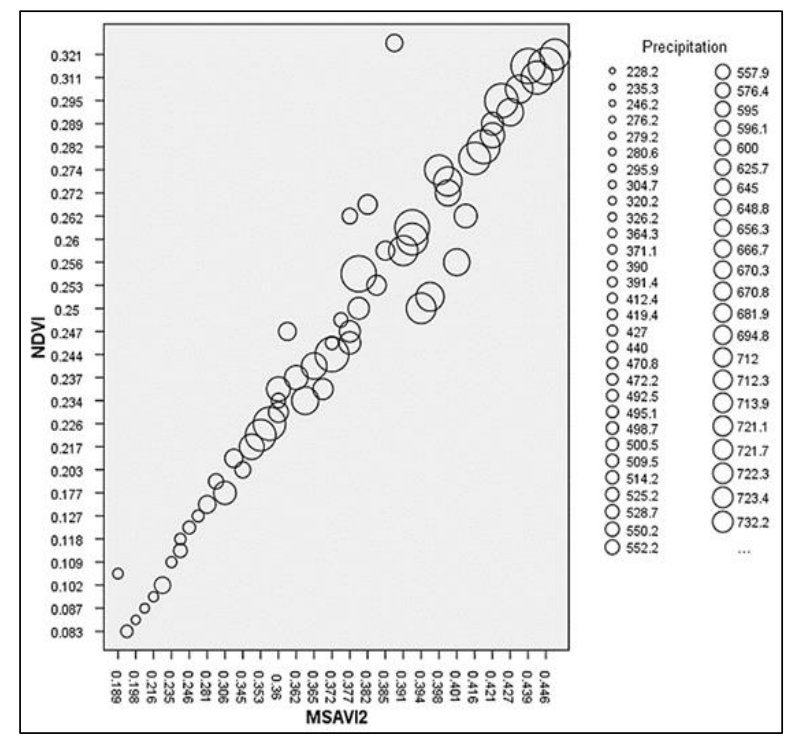

Fig. 2. The relationship between the NDVI, MSAVI2 vegetated values, and precipitation amount during 15 years from 18 sub-districts in DUG. 


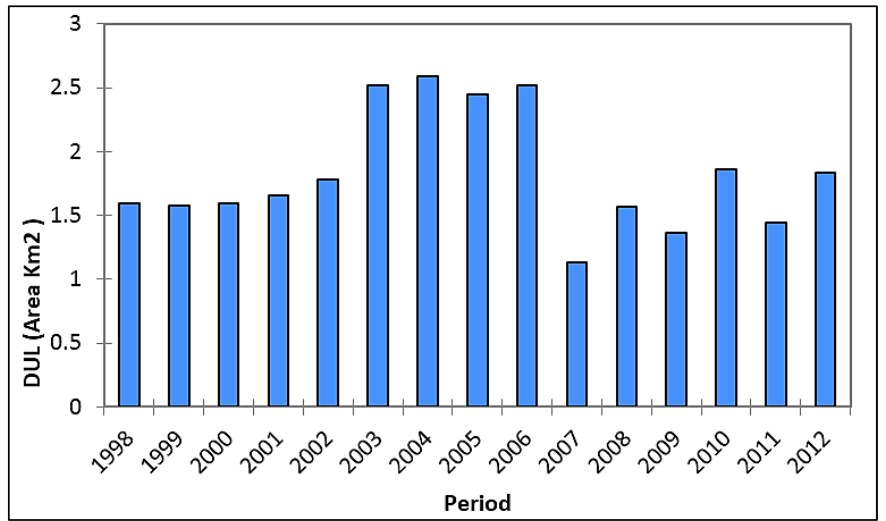

Fig. 3. LDU area changes from 1998 through 2012.

The droughts in the years 2000 and 2008 were depicted in (Fig. 6). Almost all areas were affected by drought in the growing plant season. During this season, the most significant decline in vegetation cover based on MSAVI2 occurred in the growing seasons of the year 2000. The southern, central, and southeastern parts of DUG were affected by vegetation reduction. While in 2008 , the area of vegetation cover was

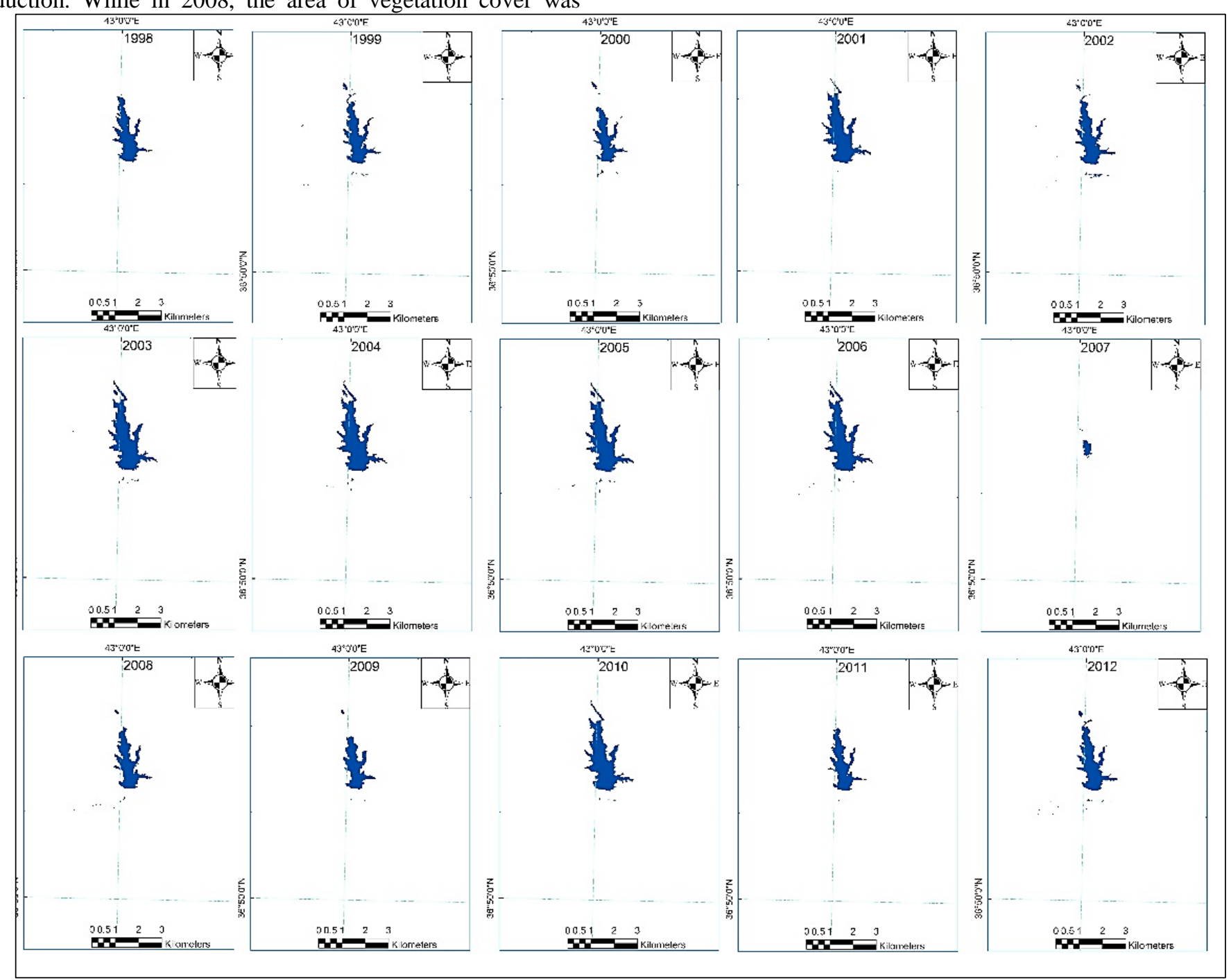

Fig. 4. Spatio-Temporal variation of the LDU-based NDWI from 1998 through 2012 in DUG.
$5,000.5 \mathrm{~km}^{2}(44.6 \%)$. This decrease may be attributed to the mismatch of seasonal precipitation and plant requirements during the critical growth stage. The decrease in vegetation cover can be linked to the climatic conditions of the study area. More specifically, an increase in precipitation averages causes an increase in the vegetation cover density. This result was also reported in $[6,20]$.

\section{The NDWI}

Changing precipitation patterns are an essential climatic indicator of drought in the water surface. The normal precipitation at a given station at any scale can be assumed to be the mean of the precipitation over 15 years. Based on this criterion, the data series was employed and used in this study. Thus, trend analysis was carried out to examine the long-term tendency of precipitation across the 15 years of DUG. The precipitation pattern map for the study area depends on the amount of annual precipitation per station (Fig. 2). This explains the map of the distribution and density of vegetation cover, depending on the amount of precipitation based on NDVI and MSAVI2. 
These changes could have affected the reservoir surface area, but so also could external human interference around the dam. The DUD has suffered from the most significant drought events in 2008-2009 throughout the Fifteen years during the period 1998-2012. The DUD surface area decline can be attributed to the decrease in the precipitation amount.

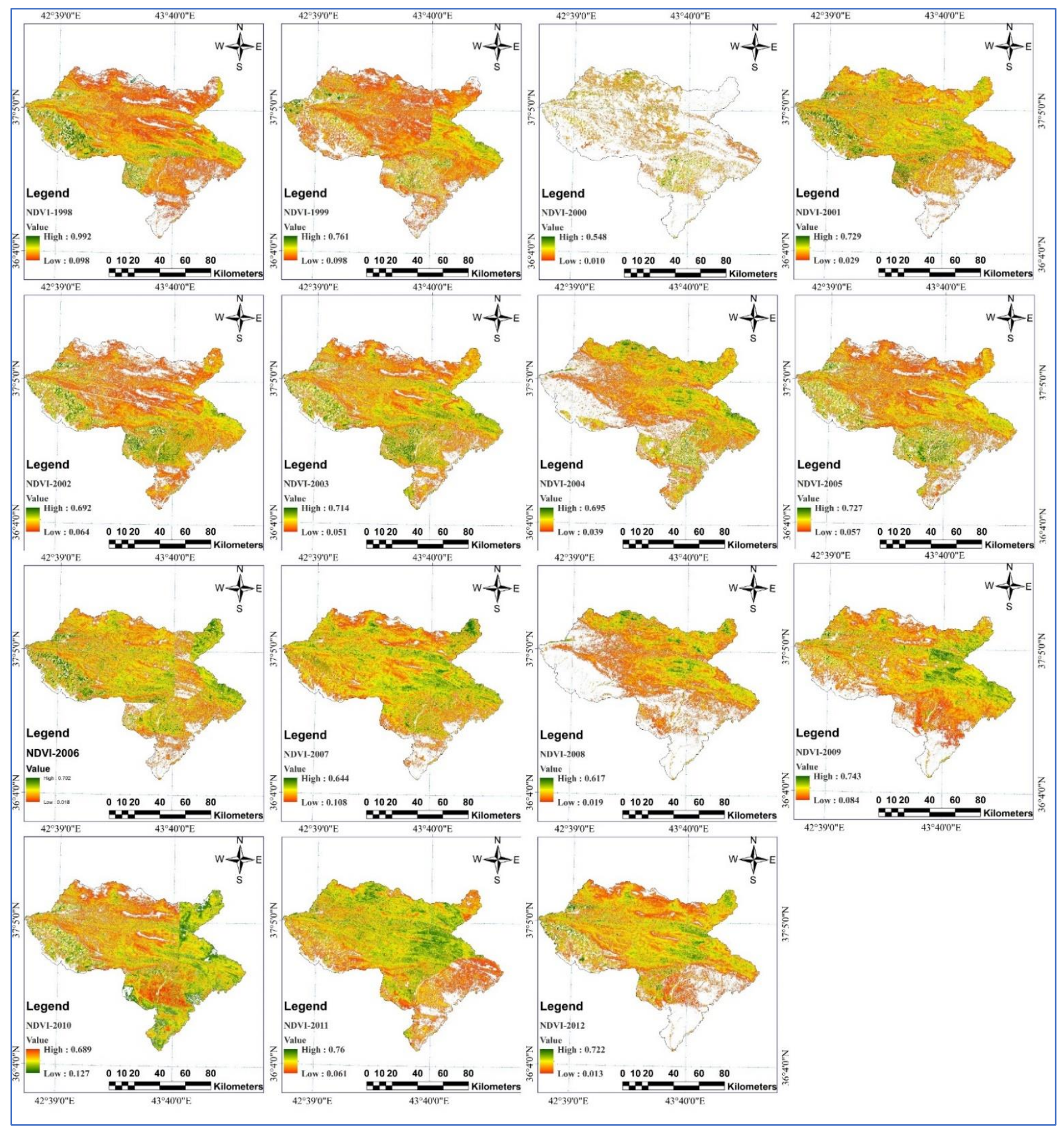

Fig. 5. Spatio-Temporal variation of the NDVI-based vegetation from 1998 through 2012 in DUG. 


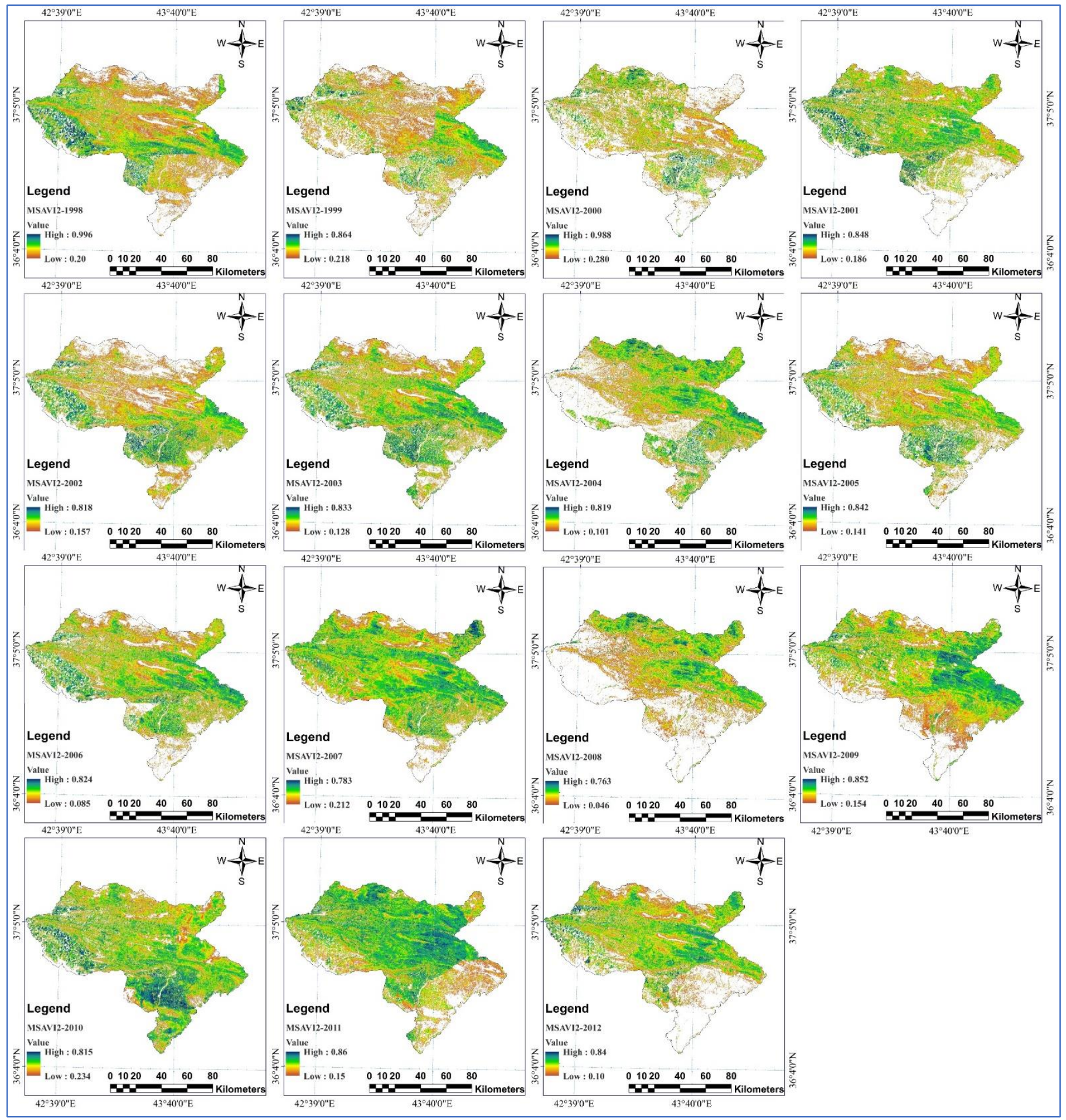

Fig. 6. Spatio-Temporal Variation of the MSAVI2-based vegetation from 1998 through 2012 in DUG.

The satellite images show that the Duhok Dam (DUD) surface area has been changed throughout the Fifteen years. Where it seized its highest levels in 2003 and 2003, 2004, 2005, and 2006, scoring 2.52, 2.59, 2.45 , and $2.52 \mathrm{~km} 2$, respectively. On the other side, in 2007,2008 , and 2009 , the DUD Water resources are linked mainly to the amount of precipitation and snowfalls on major water basins (see Fig. 3 and 4) has reached its lowest levels having $1.13,1.44$, and $1.36 \mathrm{~km} 2$, correspondingly. The surface area decline complies with the lake surface area shrinkage reported in [27].

\section{CONCLUSION}

1- Different indices measure drought in different ways, and no single index works under all circumstances. Space technology has made substantial contributions providing synoptic, wide-area coverage, and frequent information required for spatial-temporal evaluation in all the steps of a drought disaster management. 
2- In this study, the studied area was wide relative to a variety of variables such as topography and climate condition. Therefore, if make the study area smaller and focusing on it, the results may be more accurate.

3- Vegetation mapping also presents valuable information for understanding the natural and human-made environments through quantifying vegetation cover. Such an assessment and information on vegetation cover is essential for the Ministry of Agriculture and Water Resource in the IKR in order to initiate vegetation protection and restoration programs. However, this information is essential to create a proper and future plan for protecting and increasing the vegetation coverage areas in the IKR.

4- More investigations that are detailed are needed. Understand the frequency, duration, and spatial extent of drought episodes and identify most drought indices that could assist researchers, decision-makers, and drought planners for crisis-based management strategists are used for quantification of precipitation deficit at different time scales.

5- It appears that the estimates can be beneficial for the spatio-temporal extent, monitoring onset and duration of agricultural drought assessed the performance of Indices by comparing the meteorological drought indicator SPI based with the spectral indices estimates.

\section{REFERENCES}

[1] D. A. Wilhite, "Drought as a Natural Hazard," Drought A Glob. Assess., vol. 1, pp. 3-18, 2000.

[2] WMO, Integrated Drought Management Programme Handbook of Drought Indicators and Indices. 2016.

[3] A. M. Fadhil, "Land Degradation Detection using Geo-Information Technology for Some Sites in Iraq," J. Al-Nahrain Univ. Sci., vol. 12, no. 3, pp. 94-108, 2009, doi: 10.22401/jnus.12.3.13.

[4] H. A. A. Gaznayee, A. M. F. Al-Quraishi, and W. Wu, "Spatiotemporal Characteristics of Drought in the Iraqi Kurdistan Region using Landsat Time - Series Images based on VHI and VCI Indices of 1998 - 2017," ICGITA2019 Conference, Nanchang, China. 2019.

[5] L. Eklund, "Migration Patterns in Duhok Governorate, Iraq, 2000-2010," Open Geogr. J., vol. 5, no. 1, pp. 48-58, 2012, doi: $10.2174 / 1874923201205010048$.

[6] Y. T. Mustafa, "Spatiotemporal Analysis of Vegetation Cover in Kurdistan Region-Iraq using MODIS Image Data," JASTT, vol. 01, no. 01, pp. 1-6, 2020.

[7] H. A. A. Gaznayee and A. M. F. Al-Quraishi, "Analysis of Agricultural Drought's Severity and Impacts in Erbil Province, the Iraqi Kurdistan Region based on Time Series NDVI and TCI Indices for 1998 through 2017,” Jour Adv Res. Dyn. Control Syst., vol. 11, no. 11, pp. 287-297, 2019, doi: 10.5373/JARDCS/V11111/20193198.

[8] A. M. F. Al-Quraishi and A. M. Negm, Environmental Remote Sensing and GIS in Iraq, Springer-Water, Springer, Cham, ISBN: 978-3-03021344-2, 2019.

[9] S. Zakaria, Y. T. Mustafa, D. A. Mohammed, S. S. Ali, N. Al-Ansari, and S. Knutsson, "Estimation of annual harvested runoff at Sulaymaniyah Governorate, Kurdistan Region of Iraq," Nat. Sci., vol. 05, no. 12, pp. 1272-1283, 2013, doi: 10.4236/ns.2013.512155.

[10] R. Schnepf, "Iraq Agriculture and Food Supply: Background and Issues," CRS Rep. Congr., p. 57, 2004.
[11] L. Eklund, A. Abdi, and M. Islar, "From Producers to Consumers: The Challenges and Opportunities of Agricultural Development in Iraqi Kurdistan," Land, vol. 6, no. 3, p. 44, 2017, doi: 10.3390/land6020044.

[12] Y. S. Almamalachy, A. M. F. Al-Quraishi, H. Moradkhani. Agricultural Drought Monitoring Over Iraq Utilizing MODIS Products. In: AlQuraishi, A. M. F. \& Negm, A. M. (eds). Environmental Remote Sensing and GIS in Iraq. Springer-Water, Springer, Cham. https://doi.org/10.1007/978-3-030-21344-2_11. 2019.

[13] UNESCO, "Integrated drought risk management- DRM executive," Natl. Framew. IRAQ AN Anal. Rep. MARcH, vol. Second edi, no. March, 2014.

[14] P. Chopra, "Drought Risk Assessment Using Remote Sensing and GIS: A Case Study of Gujarat," p. 67, 2006, doi: 10.2741/3594.

[15] H. A. A. Gaznayee and A. M. F. Al-Quraishi, "Analysis of Agricultural Drought, Rainfall, and Crop Yield Relationships in Erbil Province, the Kurdistan Region of Iraq based on Landsat Time-Series MSAVI2," J. Adv. Res. Dyn. Control Syst., vol. 11, no. 12 Special Issue, pp. 536-545, 2019, doi: 10.5373/JARDCS/V11SP12/20193249.

[16] D. K. Menon and V. Bhavana, "An overview of Drought evaluation and monitoring using remote sensing and GIS," Pdfs.Semanticscholar.Org, vol. 3, no. 5, pp. 32-37, 2016.

[17] Y. T. Mustafa and D. R. Ismail, "Land Use Land Cover Change in Zakho District, Kurdistan Region, Iraq: Past, Current and Future," 2019 Int. Conf. Adv. Sci. Eng. ICOASE 2019, pp. 141-146, 2019, doi: 10.1109/ICOASE.2019.8723758.

[18] J. A. Foley, S. Levis, M. H. Costa, and W. Cramer, "Incorporating Dynamic Vegetation Cover within Global Climate Models David Pollard Published by: Wiley on behalf of the Ecological Society of America Stable URL: https://www.jstor.org/stable/2641227 Wiley, Ecological Society of America are collaborating," vol. 10, no. 6, pp. 1620-1632, 2018

[19] Y. T. Mustafa, "Mapping and Estimating Vegetation Coverage in Iraqi Kurdistan Region using Remote Sensing and GIS," Gen. Dir. Hortic. For. Rangeland, Minist. Agric. Water Resour. Kurdistan Reg. Iraq-FINAL Rep. 2015, vol. FINAL REPO, pp. 1-136, 2015.

[20] H. A. A. Gaznayee, "Modeling Spatio-Temporal Pattern of Drought Severity Using Meteorological Data and Geoinformatics Techniques for the Kurdistan Region of Iraq," Salahaddin University-Erbil-Iraq. Dissertation, pp. 1-11, 2020.

[21] H. Nouri, S. Beecham, S. Anderson, and P. Nagler, "High spatial resolution WorldView-2 imagery for mapping NDVI and its relationship to temporal urban landscape evapotranspiration factors," Remote Sens., vol. 6, no. 1, pp. 580-602, 2013, doi: 10.3390/rs6010580.

[22] B. Nath and S. Acharjee, "Forest Cover Change Detection using Normalized Difference Vegetation Index ( NDVI ): A Study of Reingkhyongkine Lake' s Adjoining Areas ," Indian Cartogr., vol. XXXIII, no. 2, pp. 348-403, 2013.

[23] D. do N. Aquino, O. C. da R. Neto, M. A. Moreira, A. dos S. Teixeira, and E. M. de Andrade, "Use of remote sensing to identify areas at risk of degradation in the semi-arid region," Rev. Cienc. Agron., vol. 49, no. 3 , pp. 420-429, 2018, doi: 10.5935/1806-6690.20180047.

[24] J. Qi, Y. Kerr, and A. Chehbouni, "External factor consideration in vegetation index development," Proc. 6th Int. Symp. Phys. Meas. Signatures Remote Sensing, ISPRS, no. February, pp. 723-730, 1994, doi: $95 \mathrm{~N} 17071$.

[25] J. Qi, Y. Kerr, and A. Chehbouni, "External factor consideration in vegetation index development," Proc. Phys. Meas. Signatures Remote Sens., no. August 2015, pp. 723-730, 1994.

[26] B.-c. Gao, "NDWI-A normalized difference water index for remote sensing of vegetation liquid water from space," Remote Sensing of Environment, vol. 58, pp. 257-266, 1996/12/01/ 1996.

[27] Y. T. Mustafa and M. J. Noori, "Satellite remote sensing and geographic information systems (GIS) to assess changes in the water level in the Duhok dam," Int. J. Water Resour. Environ. Eng., vol. 5, no. 6, pp. 351359, 2013, doi: 10.5897/IJWREE2012.0402. 